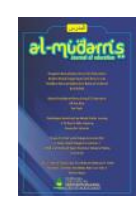

AL-MUDARRIS : journal of education, Vol. 2, No. 1 April 2019

Homepage

: http://e-journal.staima-alhikam.ac.id/index.php/al-mudarris

ISSN

DOI

: 2620-5831 (print), ISSN: 2620-4355(online)

Article type

: 10.32478/al-mudarris.v2i1.220

: Original Research Article

\title{
PENDEKATAN WEBBED LEARNING PADA PEMBELAJARAN TEMATIK TERHADAP PESERTA DIDIK INKLUSIF DI MADRASAH
}

\author{
Hasan Baharun*1, Siska Ana Astriani*2 \\ ${ }^{1}$ Program Studi Manajemen Pendidikan Islam, Pascasarjana, \\ Universitas Nurul Jadid, Paiton, Probolinggo, Jawa Timur, \\ Indonesia, \\ ${ }^{2}$ Program Studi Pendidikan Guru Madrasah Ibtidaiyah, \\ Fakultas Agama Islam, Universitas Nurul Jadid, Paiton, \\ Probolinggo, Jawa Timur, Indonesia \\ ha54nbaharun@gmail.com, siskaastriani07@gmail.com
}

\begin{abstract}
This paper presents the implementation of the webbed learning model on thematic learning on inclusive learners in Madrasah Ibtidaiyah Negeri 1 Probolinggo. Gathering normal students with inclusive students in the madrasah has many positive effects, such as arising from feeling nurturing, loving, and respecting between normal students and students with special needs. There is no treatment to choose a teacher's love for students' physical and mental differences, all must be equal and fair. Therefore, in order to streamline learning, a webbed learning approach is needed in the design of learning in heterogeneous classes. This research uses qualitative with case study. The results showed that the application of the webbed learning learning model on thematic learning of inclusive students at MIN 1 Probolinggo, used the scientific approach and active learning with the principle of joyful learning, which was carried out through; first, integration through student integration, second, integrated learning on the material, third, determining student activities, fourth, studying media and learning resources, fifth, culminating (sharing) in the form of learning evaluation.
\end{abstract}


AL-MUDARRIS:journal of education, Vol. 2. No. 1 April 2019, ISSN: 2620-5831 (print), ISSN: 2620-4355(online)

DOI: $10.32478 /$ al-mudarris.v2i1.220

Keywords : webbed learning, thematic, inclusive learners, madrasah

\begin{abstract}
Abstrak
Tulisan ini menyajikan tentang implementasi model pembelajaran webbed learning pada pembelajaran tematik terhadap peserta didik inklusif di Madrasah Ibtidaiyah Negeri 1 Probolinggo. Mengumpulkan peserta didik normal dengan peserta didik inklusif di madrasah mempunyai banyak dampak positif, seperti timbulnya rasa mengayomi, menyayangi, dan menghargai antara siswa normal dan siswa berkebutuhan khusus. Tidak ada perlakuan pilih kasih seorang guru terhadap perbedaan fisik dan mental siswa, semua harus sama dan adil. Oleh karena itu, dalam rangka mengefektifkan pembelajaran, maka diperlukan pendekatan webbed learning dalam desain pembelajaran di kelas heterogen. Penelitian ini menggunakan penelitian kualitatif jenis studi kasus. Hasil penelitian menunjukkan bahwa penerapan model pembelajaran webbed learning pada pembelajaran tematik terhadap peserta didik inklusif di MIN 1 Probolinggo, menggunakan pendekatan scientific dan active learning dengan prinsip joyfull learning, yang dilakukan melalui; Integrasi pemaduan siswa, pembelajaran terpadu pada materi, penentuan aktivitas siswa, mengkaji media dan sumber belajar, kulminasi (sharing) dalam bentuk evaluasi pembelajaran.
\end{abstract}

Keywords : webbed learning, tematik, peserta didik inklusif, madrasah

\title{
A. PENDAHULUAN
}

Pendidikan merupakan ikhitiar atau usaha sadar, terencana dan dirancang semaksimal mungkin untuk menciptakan suasana belajar yang nyaman, ${ }^{1}$ agar peserta didik dapat mengembangkan kompetensinya dalam aspek kekuatan spiritual keagamaannya, ahklaqul karimah,

1 Ismatul Izzah, 'Peran Pendidikan Agama Islam Dalam Membentuk Masyarakat Madani’, Jurnal Pedagogik, 5.1 (2018), 50-68. 
AL-MUDARRIS:journal of education, Vol. 2. No. 1 April 2019, ISSN: 2620-5831 (print), ISSN: 2620-4355(online)

DOI:

kepribadian yang baik, ${ }^{2}$ kecerdasan, pengendalian diri, serta keterampilan yang dibutuhkan dalam kehidupan sosial kemasyarakatan.

Setiap manusia yang hidup di dunia mempunyai hak untuk mendapat pendidikan yang layak, ${ }^{3}$ karena setiap individu membutuhkan pendidikan untuk mengembangkan potensi dan menemukan bakat yang dimiliki dalam dirinya. ${ }^{4}$ Sesuai dengan amanat UUD 1945 pasal 31, yang menjelaskan bahwa "Setiap warga negara Indonesia berhak mendapatkan pendidikan". 5 Hal ini menunjukkan bahwa, semua individu dari semua kalangan masyarakat, tidak memandang dari golongan keluarga kaya atau miskin, mereka mempunyai hak untuk mendapatkan pendidikan.

Pendidikan inklusif merupakan ideologi dan cita-cita pendidikan di Indonesia, dalam rangka mewujudkan pendidikan yang mengadopsi peserta didik normal dan peserta didik inklusif, tanpa ada perbedaan kelas khusus, dan peserta didik inklusif berkumpul dalam ruangan bersama pesertadidik lainnya. ${ }^{6}$

Dengan adanya pendidikan inklusif, guru bisa menanamkan rasa cinta antara peserta didik yang normal dan peserta didik berkebutuhan khusus, menciptakan suasana yang harmonis, dinamis, tolong menolong, saling menghormati dan menghargai sesama teman. Pendidikan

${ }^{2}$ Muhammad Mushfi and El Iq, 'Model Interaksi Sosial Dalam Mengelaborasi Keterampilan Sosial', Jurnal Pedagogik, 4.2 (2017), 211-27.

Nunung Dwi Setiyorini, 'Pembelajaran Kontekstual IPA Melalui Outdoor Learning Di SD Alam Ar-Ridho Semarang', AlMudarris : Journal of Education, 1.1 (2018), 30-38.

${ }^{4}$ Moch Wahid Ilham, 'Membangun High Order Thinking ( HOT ) Peserta Didik Melalui Contextual Teaching Learning ( CTL ) di Madrasah', Jurnal Islam Nusantara, 1.2 (2017), 217-27.

${ }^{5}$ Meliastari, 'Mengurangi Hiperaktifitas Pada Anak Attention Deficit/Hiperactivity Disorder (ADHD) Melalui Permainan Tradisional Teropa Tempurung', Ilmiah Pendidikan Khusus, 1.2 (2012), 283-94.

6 Abdul Rahim, 'Pendidikan Inklusif Sebagai Strategi Dalam Mewujudkan Pendidikan Untuk Semua', Trihayu, Jurnal Pendidikan Ke-SD-An, 3.1 (2016), 68-71. 
AL-MUDARRIS:journal of education, Vol. 2. No. 1 April 2019, ISSN: 2620-5831 (print), ISSN: 2620-4355(online)

DOI: $10.32478 /$ al-mudarris.v2i1.220

inklusif berkaitan erat dengan aspek kehidupan manusia yang didasarkan pada prinsip keadilan, persamaan hak, dan pengakuan terhadap hak individu. ${ }^{7}$ Semua insan di jagat raya berhak mendapat pendidikan bukan hanya peserta didik yang normal, namun peserta didik yang mempunyai kebutuhan khusus (inklusif atau disabilitas), juga memiliki hak yang sama untuk mendapatkan pendidikan yang dapat menjamin masa depannya.

Bahkan, peserta didik inklusif seharusnya banyak mendapat perhatian, bimbingan, dan binaan dari guru. Besar kemungkinan peserta didik inklusif mempunyai karya dan bakat spesial yang tidak dimiliki peserta didik yang normal. Dengan adanya keberagaman peserta didik, patut dihargai dan tidak boleh di pandang sebelah mata. Oleh karena itu, Pemerintah Indonesia memberikan jaminan kepada peserta didik inklusif yang memiliki potensi bakat spesial dan kecerdasan otak guna memperoleh pelayanan pendidikan yang baik dan bermutu. ${ }^{8}$

Fenomena yang menarik untuk dikaji di Madrasah Ibtidaiyah Negeri 1 Probolinggo adalah; adanya peserta didik inklusif yang memiliki karakter kebutuhan khusus, seperti hiperaktif yang belajar bersama siswa yang normal, peserta didik hiperaktif adalah peserta didik yang aktif bergerak. Hiperaktif dapat dilihat dari seringnya anak mengganggu teman-teman yang lain ketika pembelajaran sednag berlangsung, seperti: ramai, merusak penggaris, menyobek kertas, sering meninggalkan tempat duduk, berlari mengelilingi kelas, dan anak sering tidak menyelesaikan dan menuntaskan tugas yang telah diberikan oleh guru, sehingga peserta didik tersebut sulit menerima materi yang diajarkan guru dan penilaian hasil belajarnya rendah. ${ }^{9}$

${ }^{7}$ Hasan Baharun and Robiatul Awwaliyah, 'Pendidikan Inklusi Bagi Anak Berkebutuhan Khusus Dalam Perspektif Epistemologi Islam', MODELING: Jurnal Program Studi PGMI, 5.1 (2018), 57-71.

${ }^{8}$ Rahim.

9 Suwarno Pangesti, Putri, 'Analisis Tentang Anak Hiperaktif Dan Upaya Mengatasinya Pada Siswa Kelas IIISD Muhammadiyah 5 
AL-MUDARRIS:journal of education, Vol. 2. No. 1 April 2019, ISSN: 2620-5831 (print), ISSN: 2620-4355(online)

DOI:

Sedangkan peserta didik normal memiliki tingkat kenakalan yang berbeda-beda, juga bisa membuat situasi saat pembelajaran berlangsung menjadi gaduh, karena ulah peserta didik hiperaktif, yang suka mengganggu temantemannya yang sedang fokus belajar. Pertengkaran kerap terjadi hampir setiap hari, karena peserta didik hiperaktif tersebut yang membuat temannya menangis bahkan melaporkan kepada wali kelas, kemudian diberikan nasehat oleh guru dan disuruh meminta maaf kepada temantemannya. Namun, kejadian itu tidak menimbulkan efek jera terhadap peserta didik hiperaktif, karena karakter yang dimikili membutuhkan bimbingan dan butuh solusi untuk mengatasi kenakalannya di dalam kelas.

Teachers are one of the important factors that can determine the success or failure of students in learning ${ }^{10}$, dapat dipahami bahwa guru merupakan individu penting dalam menentukan keberhasilan atau kegagalan peserta didik dalam belajar. Dalam rangka memberikan hasil yang baik terhadap peserta didik inklusif di MIN 1 Probolinggo, khususnya siswa kelas I, II dan III, maka pembelajaran didesain sedemikian rupa, ${ }^{11}$ agar memudahkan peserta didik inklusif dalam menerima materi, yaitu melalui model webbed learning pada pembelajaran tematik. Hal ini ditujukan dalam rangka mempermudah perserta didik dalam belajar, sehingga peserta didik memiliki wawasan dan pengetahuan yang tinggi, pemahaman dan bisa menerapkan dalam kehidupan bermasyarakat.

Penggunaan webbed model merupakan inisiasi dari guru dalam mengelola kelas yang heterogen di MIN 1 Probolinggo, yaitu siswa yang inklusif dan normal. Hal

Surakarta Tahun Ajaran 2015/2016', The Progressive and Fun Education Seminar, 2016, 612-16.

${ }^{10}$ Syaiful Islam and others, 'To Boost Students 'Motivation and Achievement through Blended Learning', Journal of Physics: Conference Series, 2018, 1-11.

${ }^{11}$ Chusnul Muali, Syaiful Islam and Muhammad Mushfi El Iq Bali, 'Free Online Learning Based On Rich Internet Applications; The Experimentation Of Critical Thinking About Student Learning Style', Journal of Physics: Conference Series, 1114 (2018), 1-6. 
AL-MUDARRIS:journal of education, Vol. 2. No. 1 April 2019, ISSN: 2620-5831 (print), ISSN: 2620-4355(online)

DOI: $10.32478 /$ al-mudarris.v2i1.220

inilah yang menjadi keunikan penelitian ini, mengingat dua karakter pembelajar yang berbeda harus disatukan dan ditempatkan pada kelas yang sama, padahal, secara ideal tidak harus demikian. Peserta didik yang memiliki kelainan dalam belajarnya haruslah dilainkan dengan teman yang lainnya, agar tidak mengganggu temannya yang lain.

Akan tetapi, fakta di MIN 1 Probolinggo menunjukkan bahwa, peserta didik kelas I, II dan III heterogen dan terdiri dari peserta didik yang normal dan inklusif. Guru di kelas tersebut mampu dan bisa mengendalikan suasana kelas. Pembelajaran berjalan lancar dan efektif serta tidak ada gangguan yang berarti. Hal ini tentu sejalan dengan pernyataan dari Scott, bahwa "Inclusive education depends on the willingness and ability of teachers to facilitate and accommodate individuals with special needs". Scott menegaskan bahwa suksesnya pendidikan inklusif bergantung pada besarnya ghiroh atau keinginan dan kemampuan guru dalam memfasilitasi, mengakomodasi berbagai kebutuhan peserta didik berkebutuhan khusus. ${ }^{12}$

Keberhasilan guru tersebut tentunya disebabkan oleh adanya pendekatan yang tepat guna dalam pembelajarannya, yaitu dengan menerapkan pendekatan tematik model jaring laba-laba atau Spider webbed/webbed. Guru yakin, bahwa keberadaan mereka merupakan peluang bagi tenaga pendidik untuk meningkatkan kompetensi dan sumber belajar bagi teman-teman lain untuk mengembangkan sikap-sikap positif. ${ }^{13}$ Dengan begitu, siswa akan merasakan hal positif, betah dan nyaman di dalam kelas, tanpa harus diganggu oleh temannya yang lain.

${ }^{12} \mathrm{Ni}$ Suwaryantini, Sulastri and Ni Suami, 'Pengaruh Media Kartu Berseri Melalui ModelPembelajaran Terpadu Tipe Webbed Terhadap Hasil Belajar Membaca Permulaan', E-Journal MIMBAR Universitas Pendidikan Ganesha, 2.1 (2014).

${ }^{13}$ Yvonne J John, 'A “ New " Thematic , Integrated Curriculum for Primary Schools of Trinidad and Tobago: A Paradigm Shift', International Journal of Higher Education, 4.3 (2015), 172-87 <http://dx.doi.org/10.5430/ijhe.v4n3p172>. 
AL-MUDARRIS:journal of education, Vol. 2. No. 1 April 2019, ISSN: 2620-5831 (print), ISSN: 2620-4355(online)

DOI:

\section{B. KAJIAN TEORI}

\section{Pendidikan Inklusif di Madrasah}

Pendidikan inklusif merupakan system lembaga pendidikan yang mengatur agar siswa yang menyandang status kebutuhan khusus (disabilitas) mendapatkan pelayanan yang sama di kelas regular bersama teman-teman seusianya, tanpa harus ada perbedaan antara siswa penyandang berkebutuhan khusus dengan siswa yang normal, supaya bisa mendukung semua kegiatan siswa tanpa terkecuali. Inclusive education is an effort to provide opportunities, justice and equal rights to students with special needs to regular attendance or public schools. Artinya pendidikan inklusif merupakan upaya dalam pendidikan, untuk memberikan siswa yang dianggap memiliki kebutuhan khusus, dengan peluang untuk keadilan dan persamaan hak untuk menghadiri sekolah regular atau umum. ${ }^{14}$

Mengumpulkan peserta didik normal dengan peserta didik inklusif di madrasah mempunyai banyak dampak positif, seperti timbulnya rasa mengayomi, menyayangi, dan menghargai antara siswa normal dan siswa berkebutuhan khusus. Tidak ada perlakuan pilih kasih seorang guru terhadap perbedaan fisik dan mental siswa, semua harus sama dan adil. Istilah inklusif dalam dunia pendidikan mempunyai arti yang sangat luas. Inklusif dapat dihubungkan dengan adanya persamaan atau kesetaraan hak perseorangan dalam pembagian sumber-sumber tertentu, seperti politik, pendidikan, sosial, dan ekonomi. ${ }^{15}$ Pengertian lain dari pendidikan inklusif merupakan sistem pendidikan yang menyatukan layanan Pendidikan Luar Biasa (PLB) dengan sistem Pendidikan Reguler pada satu

${ }^{14}$ Nofita Sari Astanu, Sowiyah and Irwan Suntoro, 'Implementasi Program Pendidikan Inklusif (Studi Evaluasi Metode CIPP Di SMA Negeri 2 Metro)', JMMP, 1.1 (2015).

${ }^{15}$ Pahrizal Iqrom, Andi Gani and Khairul Muluk, 'Manajemen Pelayanan Pendidikan Inklusif', Jurnal Pendidikan Humaniora, 2.4 (2014), 322-26. 
AL-MUDARRIS:journal of education, Vol. 2. No. 1 April 2019, ISSN: 2620-5831 (print), ISSN: 2620-4355(online)

DOI: $10.32478 /$ al-mudarris.v2i1.220

sistem pendidikan di sekolah biasa. ${ }^{16}$

Pendidikan inklusif dan pendidikan regular dikatakan dua hal yang tidak dapat digabungkan, dua hal tersebut sangat sekali berbeda ${ }^{17}$. Bertolak dengan semboyan Negara kita bhineka tunggal ika Pernyataan tersebut mempunyai arti berbeda-beda tetapi satu, kelainan (kecacatan) dan keberbakatan istimewa hanyalah suatu bentuk kebhinekaan seperti halnya keberagaman suku, ras, bahasa budaya, atau agama yang ada di Negara Indonesia. ${ }^{18}$

Selama guru mampu menggabungkan anak berkebutuhan khusus dengan anak normal di kelas, maka pendidikan inklusif sangat bagus untuk diimplementasikan, karena kebanyakan sekolah-sekolah luar biasa sangat berbeda sekali dengan sekolah regular. ${ }^{19}$ Sekolah luar biasa terlihat menyeramkan, kumuh, dan interior kelasnya tidak menarik. Apalagi sekolah luar biasa yang berada di desadesa tidak pernah mendapat perhatian baik dari pemerintah dan masyarakat. Seharusnya sekolah didesain dengan indah, rapi dan menarik supaya siswa betah dan nyaman saat berada di lingkungan sekolah.

Dalam perspketif Islam, inklusif dipahami sebagai suatu bentuk keterbukaan Islam terhadap realitas kemajemukan manusia. ${ }^{20}$ Dalam pandangan Islam inklusif dalam bingkai rahmatan lil 'alaminn (rahmat bagi seluruh

${ }^{16}$ Trimo, 'Manajemen Sekolah Penyelenggara Pendidikan Inklusif: Kajian Aplikatif Pentingnya Menghargai Keberagaman Bagi Anak-Anak Berkebutuhan Khusus', JMP, 1.2 (2012), 224-39.

${ }^{17}$ Mumpuniarti, Fathurroman and Sukinah, 'Value-Based Education Model to Build Students of Inclusive Elementary School' S Character', DiIJE, 2 (2014), 1-10.

${ }^{18}$ Jaya Eka, 'Pendidikan Multikultur: Membangun Keberagaman Inklusif Dan Moderat Di Kalimantan', Jurnal KHAZANAH PENDIDIKAN, 5.2 (2013), 1-9.

${ }^{19}$ Erni Murniarti and Nouf Zahra Anastasia, 'Pendidikan Inklusif Di Tingkat Sekolah Konsep, Implementasi, Dan Strategi', JDP, 9.1 (2016), 9-18.

${ }^{20}$ Hazel Bines and Philippa Lei, 'International Journal of Educational Development Disability and Education : The Longest Road to Inclusion', International Jurnal of Education Development, 31 (2011), 419-24 <http://dx.doi.org/10.1016/j.ijedudev.2011.04.009>. 
DOI:

alam) dimaknai keterbukaan, yang menjadi sikap dasar mayoritas umat Islam, sehingga mampu hidup berdampingan secara damai dan bekerjasama dengan orang yang berbeda keyakinan agama atas dasar saling memahami, menghargai, dan mempercayai. ${ }^{21}$

Konsepsi tentang pendidikan inklusif, pada hakikatnya telah ada dalam Islam, yaitu dengan diciptakannya makhluq Allah yang bervariasi sebagai bukti kekuasaan Allah SWT, mulai dari perbedaan bahasa dan warna kulit manusia, melalui firmannya dalam QS. Al-Rum :22;

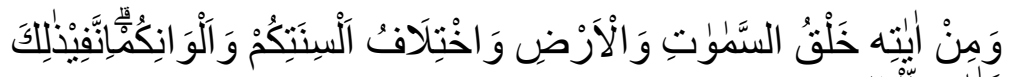

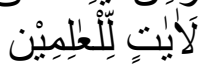

Pendidikan inklusif di madrasah bertujuan memberikan kesempatan dan peluang kepada peserta didik inklusif yang memiliki kelainan mental, emosional, fisik dan sosial atau memiliki kompetensi, kecerdasan atau keterampilan dalam berkarya untuk mendapatkan pendidikan yang baik dan berkualitas sesuai dengan kebutuhan dan kemampuan masing-masing peserta didik penyandang status berkebutuhan khusus. ${ }^{22}$ Peserta didik penyandang berkebutuhan khusus harus di bimbing semaksimal mungkin, karena setiap peserta didik memiliki bakat dan keahliannya sendiri.

Oleh sebab itu, memberikan kesempatan jalan yang lebih baik untuk membangkitkan semangat anak didik berkebutuhan khusus supaya tidak merasa dikucilkan di masyarakat. Dengan adanya pendidikan inklusif akan lebih mudah berinteraksi dengan teman, keluarga dan orangorang sekitarnya. Karena dengan pendidikan mereka mempunyai bekal dalam bermasyarakat dan bisa berinteraksi dengan baik dengan orang lain.

${ }^{21}$ Rahim.

${ }^{22}$ Abdul Salim, 'The Prevalence of Children With Special Needs In Inclusive Elementary Schools in Iodine Deficiency Area', DIJE, 1 (2013), 40-46. 
AL-MUDARRIS:journal of education, Vol. 2. No. 1 April 2019, ISSN: 2620-5831 (print), ISSN: 2620-4355(online)

DOI: $10.32478 /$ al-mudarris.v2i1.220

Madrasah, merupakan lembaga pendidikan keagamaan yang menerima peserta didik inklusif yang memiliki perbedaan dan potensi kecerdasan serta bakat, guna mengikuti pembelajaran secara bersama-sama dan dalam ruangan yang sama dengan peserta didik lain pada umumnya. ${ }^{23}$ Semua peserta didik diajarkan dan dibiasakan mengikuti kegiatan-kegiatan madrasah seperti sholat dhuha, belajar membaca, menulis qur'an dan menghafal surat-surat pendek, serta kegiatan ektrakurikuler seperti marching band, musik, pramuka, pecinta alam dan lain sebagainya. Pada kegiatan tersebut semua peserta didik harus mengikuti tanpa ada perbedaan antara peserta didik normal dan peserta didik inklusif.

Inklusif juga disebut sebagai pelibatan berbagai kelompok sosial masyarakat dalam proses pengambilan keputusan yang bijaksana dan biasanya menekankan keterlibatan kelompok yang terabaikan keberadaannya atau termarjinalkan oleh golongan masyarakat yang memiliki kekuatan sosial ekonomi yang ada. ${ }^{24}$ Salamanca menjelaskan bahwa "prinsip yang mendasar dari pendidikan inklusif yaitu, semua anak sepantasnya belajar secara bersama-sama tanpa harus melihat kesulitan ataupun perbedaan mental, psikis ataupun fisik yang ada pada diri mereka." 25

Pendidikan inklusif adalah hak asasi setiap peserta didik dan ini bisa dikatakan pendidikan yang baik untuk meningkatkan toleransi sosial. ${ }^{26}$ Pendidikan inklusif juga didesain untuk menghargai persamaan hak, keberagaman masyarakat atas pendidikan yang ditempuh tanpa membedakan gender, usia, bahasa, etnik, kecacatan, dan

${ }^{23}$ Tias Martika and Abdul Salim, 'Comparative Study of Regular Teachers ' Special Education Pedagogy Competence Level In Elementary and Senior High Inclusive School', Journal of ICSAR, 1.1 (2017), 32-35.

${ }^{24}$ Sari Rudiyati, 'Peningkatan Kompetensi Guru Sekolah Inklisif Dalam Penanganan Anak Berkebutuhan Pendidikan Khusus Melalui Pembelajaran Kolaboratif', UNY JOURNAL, 2013, 296-306.

${ }^{25}$ Astanu, Sowiyah and Suntoro.

${ }^{26}$ Trimo. 
AL-MUDARRIS:journal of education, Vol. 2. No. 1 April 2019, ISSN: 2620-5831 (print), ISSN: 2620-4355(online)

DOI:

lain-lain. $^{27}$

Pendidikan inklusif dapat diselenggarakan di madrasah dengan peserta didik yang mayoritas beragama Islam. ${ }^{28}$ Pendidikan inklusif di madrasah harus menciptakan suasana yang harmonis dan menjaga kekerabatan kelas yang ramah dan terbuka dalam menerima keanekaragaman dan menghargai perbedaan yang ada, dan tentunya akan ada perbedaan cara peserta didik dalam berfikir untuk memahami materi, khususnya peserta didik inklusif yang membutuhkan perhatian lebih di saat pembelajaran berlangsung. Dengan adanya perbedaan peserta didik aktivitas kelas dapat mendorong peserta didik yang lebih mampu untuk membantu peserta didik inklusif (tutor sebaya). ${ }^{29}$

Jika dilihat dari kekurangan peserta inklusif di madrasah, memang secara lahiriyah tidak memiliki bakat yang istimewa. Namun, setiap manusia yang diciptakan memiliki keistimewaan sendiri. Bakat yang tersembunyi akan muncul ketika ada bimbingan dan binaan secara khusus. Penggunaan strategi pembelajaran yang optimal mampu mengembangkan hidden skills siswa. ${ }^{30}$ Oleh sebab itu, anak berkebutuhan khusus harus dididik dengan cara yang baik serta menggunakan fasilitas yang bagus.

\section{Pembelajaran Terpadu Model Webbed}

Webbed learning adalah pembelajaran terpadu yang menggunakan pendekatan tematik yang dikembangkan menjadi suatu tema yang telah ditentukan kepada peserta didik, agar supaya tercipta pembelajaran yang efektif dan seluruh peserta didik merasa nyaman menerima materi

${ }^{27}$ Suharta, 'Pendekatan Inklusif Dan Deliberatif Dalam Perencanaan Pendidikan Kecakapan Hidup Dan Pemberdayaan Masyarakat Miskin', Diklus Edisi 6, 2007, 64-84.

${ }^{28}$ Murniarti and Anastasia.

${ }^{29}$ Siti Anafiah and Dinar Westri Andini, 'Pelaksanaan Pendidikan Inklusi Di SD Tumbuh 2 Yogyakarta', Wacana Akademika, 2.1 (2018), 73-84.

${ }^{30}$ Muhammad Mushfi El Iq Bali, Strategi Pembelajaran Pendidikan Agama Islam (Probolinggo: Pustaka Nurja, 2018). 
dengan model pembelajaran dan metode mengajar bervariasi, pemilihan model pembelajaran harus berdasarkan Kompetensi Inti (KI) dan Kompetensi Dasar (KD). ${ }^{31}$ Keterpaduan yang digunakan difokuskan pada model pembelajaran spider webbed/webbed learning. ${ }^{32}$ Menurut Robin Fogarty model pembelajaran webbedyang paling populer dalam model pembelajaran terpadu lainnya. ${ }^{33}$

The webbed model of integration views the curriculum through a telescope, capturing an entire constellation of disciplines as well as the needs of students. ${ }^{34}$ Model webbed (jaring laba-laba) merupakan suatu pendekatan tematik sebagai pemadu muatan pelajaran,bahan ajar dan kegiatan pembelajaran, baik lintas mata pelajaran maupun dalam pelajaran tertentu. ${ }^{35}$ Model webbed lebih sesuai diterapkan pada kelas-kelas rendah, sebab berkaitan dengan penambahan pengetahuan dan mengiringi perkembangan mental siswa yang ada dikelas rendah. Model webbed merupakan pembelajaran yang menggunakan tema -tema tertentu yang berkecenderungan dapat disampaikan melalui beberapamuatan mata pelajaran yang diintegrasikan. ${ }^{36}$

Model webbed dengan jaring laba-laba, artinya interkoneksi kendati didasari latar tema yang berbeda, namun tema inti ditetapkan sesuai kebutuhan dan minat siswa. ${ }^{37}$ Untuk lebih terinci penerapan model pembelajaran webbed ini, dimulai dari tahap penyusunanperencanaan

${ }^{31}$ Asep Herry Hernawan, 'Pengembangan Model Pembelajaran Tematik Di Kelas Awal Sekolah Dasar’, 2009.

${ }^{32}$ Muhammad Yusuf and Ana Ratna Wulan, 'Penerapan Model Pembelajaran Discovery Learning Menggunakan Pembelajaran Tipe Shared Dan Webbed Untuk Meningkatkan Keterampilan Proses Sains', JPPPF-Jurnal Penelitian \& Pengembangan Pendidikan Fisika, 1.2 (2015), 19.

${ }^{33}$ Hernawan.

${ }^{34}$ Astanu, Sowiyah and Suntoro.

${ }^{35}$ Mumpuniarti, Fathurroman and Sukinah.

${ }^{36}$ Mumpuniarti, Fathurroman and Sukinah.

${ }^{37}$ Robin Fogarty, 'Ten Ways to Integrate Curriculum', Integrating the Curriculum, 1991, 61-65. 
AL-MUDARRIS:journal of education, Vol. 2. No. 1 April 2019, ISSN: 2620-5831 (print), ISSN: 2620-4355(online)

DOI:

yang matang. Tahap ini meliputi perencanaan mata pelajaran yang akan diintegrasikan melalui, mempelajari kompetensi dasar, membuat dan menentukan tema yang tepat, serta indikatornya, dan membentuk pemetaan sebaik mungkin sebagai sarana stimulan bagipeserta didik, dan diakhiri dengan penyusunan silabus. ${ }^{38}$

Webbed curricula use a thematic approach to integrating subject matter. Broad themes provide a greater opportunity for teachers of various disciplines to find common topics, concepts, and skills. ${ }^{39}$ Webbed lebih memfokuskan pada keterlibatan peserta didik secara aktif dalam proses pembelajaran. Peserta didik dalam hal ini menjadi subyek dan guru sebagai fasilitator dan pengarah. Melalui hal tersebut, peserta didik dapat memperoleh pengalaman langsung dari hasil kerjanya dan terlatih untuk mendapatkan sendiri pengetahuannya saat pelajaran berlangsung. ${ }^{40}$

Trianto menerangkan bahwa "pembelajaran terpadu model webbed merupakan pembelajaran yang memakai pendekatan tematik, yang pemaduan antar mata pelajarannya saling berkesinambungan. Pengembangannya dimulai dari menentukan tema tertentu yang sesuai dengan lingkungan siswa. Tema bisa diterapkan denganhasil kesepakatan antara guru dan siswa, tetapi dapat pula dengan cara diskusi sesama guru". ${ }^{41}$

Dari berbagai pengertian di atas, model pembelajaran yang paling populer adalah model pembelajaran webbed. Dalam hubungan ini tema ada garis penghubung antara tema sentra dan sub-subtema, kemudian juga ada garis penghubung antara muatan mata pelajaran.

38 Alfiah and Siti Fitriana, 'Pengaruh Pembelajaran Terpadu Model Webbed (Jaring Laba-Laba) Dan Model Fragmented (Penggalan) Terhadap Hasil Belajar Unggah-Ungguhing Bahasa Jawa Di Kelas Awal Sekolah Dasar', Journal Universitas PGRI Semarang, 2012.

39 Tasrif Syam, 'Memperkenalkan Hak Asasi Manusia Pada Siswa ( SD ) Melalui Pembelajaran Terpadu Dengan Model Webbed', Keguruan, 1.1 (2013), 29-32.

${ }^{40}$ Syam. 
AL-MUDARRIS:journal of education, Vol. 2. No. 1 April 2019, ISSN: 2620-5831 (print), ISSN: 2620-4355(online)

DOI: $10.32478 /$ al-mudarris.v2i1.220

Untuk membantu memahami model ini, dapat disajikan sebagai berikut;

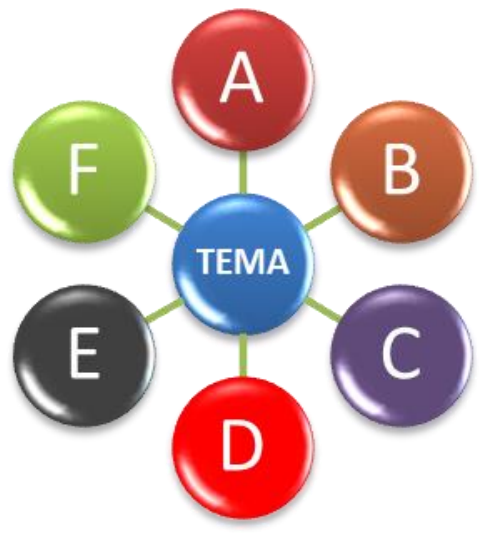

Webbed learning sebagai pembelajaran terpadu yang menggunakan pendekatan tematik, pengembangannya dimulai dari menentukan tema yang akan diangkat, kemudian dikembangakan menjadi beberapa subtema, dan cara membuatnya dengan membuat jaring-jaring tema seperti gambar di atas, kemudian menentukan kegiatan atau aktivitas pada setiap bidang pengembangan dengan mengacu pada silabus. ${ }^{42}$

Karakteristik yang perlu dipahami dari tipe model webbed learning, yaitu:

a. Berpusat pada siswa (student centered) siswa yang mempunyai banyak peran dalam pembelajaran dan guru sebagai fasilitator,

b. Menjadi pengalaman langsung bagi siswa (direct experiences) dansiswa dihadapkan dengan sesuatu yang konkrit,

c. Pemisahan antar mata pelajaran yang satu dengan lainnya menjadi tidak begitu jelas, pembelajaran difokuskan pada pembahasan tema-tema yang sesuai dan berkaitan erat dengan kehidupan siswa,

\footnotetext{
${ }^{42}$ Yusuf and Wulan.
} 
AL-MUDARRIS:journal of education, Vol. 2. No. 1 April 2019, ISSN: 2620-5831 (print), ISSN: 2620-4355(online)

DOI:

d. Menyajikan konsep berbagai muatan mata pelajaran dalam suatu proses pembelajaran. ${ }^{43}$

Adapun kelebihan guru dalam menerapkan model webbed learning di kelas adalah;

a. Peserta didik dapat melihat aktivitas atau ide-ide yang berbeda dari tema-tema yang diminati,

b. Mudah diparktikkan oleh guru yang masih belum memiliki pengalaman mengajar,

c. Memudahkan perencanaan kerja kelompok,

d. Kompetensi dasar dapat dikembangkan dengan cara mengaitkan mata pelajaran lain dengan pengalaman pribadi siswa,

e. Lebih dapat dirasakan manfaaatnya oleh siswa, karena materi yang diajarkan dalam bentuk tema yang jelas. ${ }^{44}$

Webbed learning yang diterapkan oleh guru di dalam kelas, akan efektif manakala dirancang dan didesain dengan baik oleh guru dengan prinsip continous improvement.

\section{METODE PENELITIAN}

Penelitian ini menggunakan pendekatan kualitatif jenis studi kasus. Tekhnik pengumpulan datanya dilakukan melalui; wawancara, observasi, dokumentasi dan focus group discussion. Analisis datanya dilakukan secara sirkuler, mulai dari reduksi data, penyajian data dan diakhiri dengan penarikan kesimpulan.

\section{TEMUAN DAN PEMBAHASAN}

Hasil penelitian menunjukkan bahwa; dalam kegiatan pembelajaran di MIN 1 Probolinggo, khususnya kelas I, II dan III, di mana karakter peserta didiknya heterogen, terdiri dari peserta didik inklusif dan peserta didik normal. Hasil penelitian menunjukkan bahwa,

${ }^{43}$ Hernawan.

${ }^{44}$ Hanik Wijayanti, Suhartono and Joharman, 'Penggunaan Model Pembelajaran Tematik (Webbed) nDalam Peningkatan Pemebelajaran Tema Pengalaman Di Kelas II SD Negeri 5 Kebumen Tahun Ajaran 2013/2014', FKIP UNS JOURNAL SYSTEMS, 5.3 (2014), 2017. 
AL-MUDARRIS:journal of education, Vol. 2. No. 1 April 2019, ISSN: 2620-5831 (print), ISSN: 2620-4355(online)

DOI: $10.32478 /$ al-mudarris.v2i1.220

ditemukan kesulitan belajar yang dihadapi oleh peserta didik inklusif di MIN 1 Probolinggo, terkait dengan penerimaan materi yang di sampaikan oleh guru, khususnya bagi peserta didik yang menyandang berkebutuhan khusus, yang memiliki keunikan dalam beraktivitas. Biasanya anak tersebut terlalu banyak bergerak, sulit dikendalikan, tidak focus, tidak kenal lelah, dan implusif.

Kesulitan belajar tersebut terjadi karena tingkat kecerdasan peserta didik inkulusif berbeda, serta tingkat kenakalannya juga berbeda. Ada beberapa faktor kesulitan belajar di kelas I, II dan III yaitu:

1. Adanya peserta didik yang hiperaktif, dalam hal ini peserta didik hiperaktif sulit dikendalikan, terlalu banyak bergerak, tidak focus, implusif, dan sering menggangu temannya saat pembelajaran berlangsung.

2. Adanya peserta didik slow learner (lamban belajar) yang kecerdasan intelektualnya rendah dibawah siswa normal.

3. Peserta didik yang masih belum bisa membaca, sehingga sulit untuk mengerjakan tugas dan menjawab soal-soal dengan benar.

Dari kesulitan yang dihadapi oleh peserta didik tersebut di atas, guru menerapkan pendekatan webbed learning pada pembelajaran tematik dalam kegiatan pembelajarannya. Webbed learning yang diaplikasikan pada pembelajaran tematik diidentikkan dengan jaring laba-laba, artinya di dalam tema ada beberapa mata pelajaran yang pembahasannya saling berkesinambungan antara yang satu dengan lainnya, dan tujuan dari diangakatnya tema tersebut bisa tercapai.

Alur pelaksanaan model pembelajaran webbed learning pada pembelajaran tematik yang didesain oleh guru sebagai berikut; 


\section{DOI:}

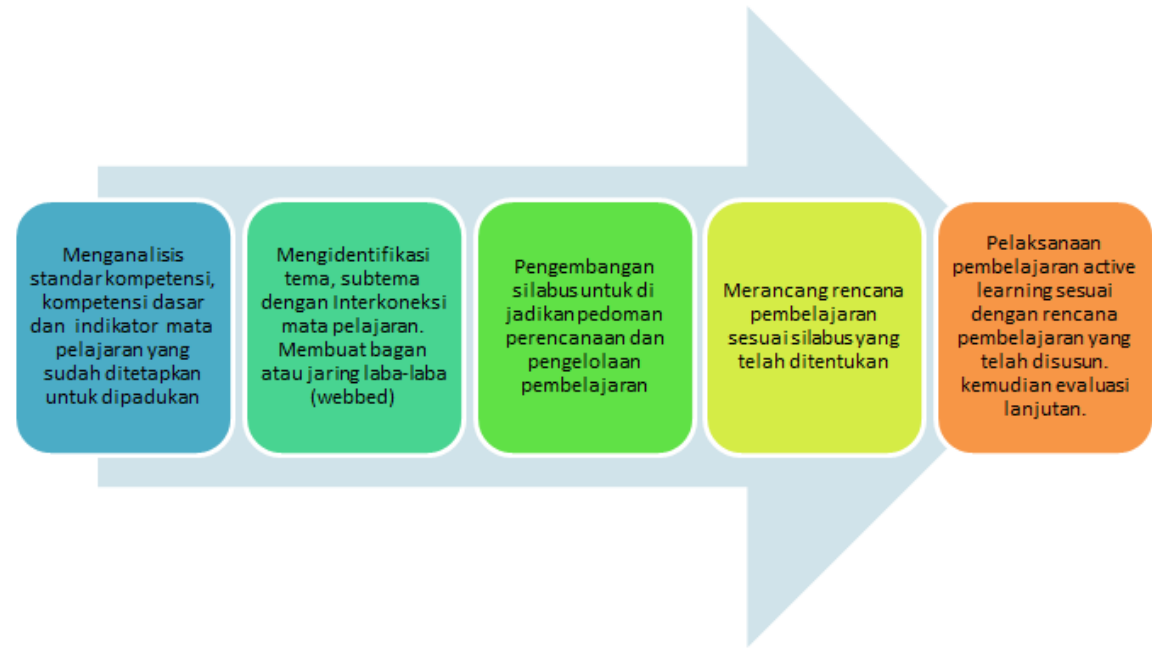

Gambar 1 :

Alur webbed learning pada pembelajaran tematik

Dalam praktiknya, penerapan model pembelajaran webbed learning pada pembelajaran tematik di kelas I, II dan III MIN 1 Probolinggo terhadap peserta didik inklusif, menggunakan pendekatan scientific dan active learning dengan prinsip joyfull learning atau pembelajaran yang menyenangkan. Adapun implementasi webbed learning pada pembelajaran tematik di MIN 1 Probolinggo dapat dijabarkan sebagai berikut;

1. Integrasi melalui Pemaduan Siswa

Integrasi melalui pemaduan siswa merupakan cara memadukan beberapa peserta didik inklusif dengan peserta didik normal. Hal ini dilakukan melalui analisis terhadap peserta didik guna mendapatkan informasi tentang rekam jejak mereka. Analisis terhadap peserta didik yang dilakukan di MIN 1 Probolinggo meliputi;

Pertama, karakteristik peserta didik atau keadaan yang berhubungan dengan kemampuan dalam berfikir dan kecerdasan intelektual peserta didik. Kedua, psikologi peserta didik atau yang berkenaan dengan perkembangan tingkah laku yang berada pada tahap usia anak sekolah dasar atau madrasah ibtidaiyah. Dengan memahami 
AL-MUDARRIS:journal of education, Vol. 2. No. 1 April 2019, ISSN: 2620-5831 (print), ISSN: 2620-4355(online)

DOI: $10.32478 /$ al-mudarris.v2i1.220

psikologi peserta didik, guru MIN 1 Probolinggo bisa dengan mudah mengetahui kepribadian, kecerdasan, minat bakat dan tingkah laku peserta didik. Ketiga, latar belakang peserta didik atau yang berhubungan dengan latar belakang keluarga, baik dari aspek ekonomi dan status sosial. Keempat, gaya belajar peserta didik atau yang berhubungan dengan kebiasaan belajar yang mampu mempercepat pemahaman terhadap materi yang di ajarkan oleh guru.

Dengan mengenali beberapa karakteristik individu peserta didik, guru dapat menentukan desain pembelajarannya, yaitu dengan menggunakan webbed learning pada pembelajaran tematik. Di samping itu, guru MIN I Probolinggo juga dapat menentukan bagaimana perlakuan yang harus diterapkan terhadap masing-masing peserta didik, dan perlakuan khusus terhadap peserta didik hiperaktif, memilih metode dan media yang akan digunakan, serta bagaimana cara mengelola kelas dengan baik dan efektif.

2. Pembelajaran Terpadu pada Materi

Pembelajaran terpadu pada materi merupakan cara memadukan materi dari beberapa muatan pelajaran (matematika, ilmu pengetahuan alam, ilmu pengetahuan sosial, kewarganegaraan, bahasa Indonesia, seni budaya dan prakarya) ke dalam satu kegiatan pembelajaran yang diintegrasikan menggunakan topik-topik (tema-tema).

Pada tahapan ini, guru secara bersama-sama mempelajari Kompetensi Dasar yang akan dicapai, kemudian dijabarkan menjadi indikator muatan tema. Ada 6 mata pelajaran yang diintegrasikan dalam tema yaitu: Ilmu Pengetahuan Sosial, Bahasa Indonesia, Matematika, Ilmu Pengetahuan Alam, Pendidikan Kewarganegaraan, SeniBudaya dan Prakarya.

Setelah itu, guru MIN 1 Probolinggo menentukan tema sentral yang dikembangkan menjadi beberapa subtema yang telah terkoneksi dengan 6 muatan mata pelajaran. Merancang bagan atau jaring laba-laba supaya konsep antar tema, sub-sub tema dan muatan pelajaran tertata dan terstruktur dengan baik. Sedangkan pengangkatan judul 
AL-MUDARRIS:journal of education, Vol. 2. No. 1 April 2019, ISSN: 2620-5831 (print), ISSN: 2620-4355(online)

DOI:

tema sudah ditentukan oleh kurikulum 2013, hanya saja guru MIN 1 Probolinggo memilih tema yang sesuai dengan kompetensi dasar, indikator, dan kebutuhan siswa.

Untuk mencapai tujuan pembelajaran dengan model webbed learning pada pembelajaran tematik bagi peserta didik inklusif, guru menggunakan pendekatan religius. Artinya guru mengawali pembelajaran dengan pembacaan doa dengan harapan proses belajar mengajar berjalan dengan baik dan materi yang diajarkan bisa dipahami, dikuasai serta bisa dikembangkan oleh peserta didik. Pada akhir pertemuan guru mengajak siswa untuk menutup pembelajaran dengan pembacaan doa bersama sebagai rasa syukur atas ilmu-ilmu yang diperoleh, dengan harapan ilmu yang sudah diajarkan dapat bermanfaat dan barokah.

Tujuan dari pendekatan religius ini supaya peserta didik bisa membiasakan diri untuk selalu bersyukur kepada Allah SWT. atas ilmu-ilmu yang didapatkan di bangku sekolah. Dan diberikemudahandalam menuntut ilmu.

3. Penentuan Aktivitas Siswa

Pelaksanaan model pembelajaran webbed learning pada pembelajaran tematik yang bersifat student centered lebih memungkinkan peserta didik dapat berpartisipasi aktif dalam mengikuti proses pembelajaran, baik secara individu maupun kelompok. Ditambah dengan menggunakan pendekatan scientific serta metode pembelajaran active learning dan joyfull learning yang digunakan untuk membuat suasana belajar yang menyenangkan, dengan tanpa membeda-bedakan karakter siswa, baik siswa normal maupun siswa inklusif.

Penggunaan metode yang bervariasi dan menyenangkan mampu mempengaruhi keaktifan peserta didik normal dan peserta didik hiperaktif dalam belajarnya. Aktifitas siswa dalam mengkuti pembelajaran disesuaikan dengan tema yang diajarkan, siswa dapat mengamati gambar, mencari kosakata, membaca nyaring, bercerita, menambahkan kata, bernyanyi bersama, menghitung, praktik, dan banyak kegiatan lainnya yang bisa dilakukan peserta didik di dalam kelas. 
Dalam kegiatan ini, guru di MIN 1 Probolinggo mampu menciptakan suasana belajar seperti bermain, karena di waktu peserta didik bermain, mereka tidak menyadari bahwa mereka telah belajar. Pada saat bermain, apa yang mereka lihat, yang mereka dengar, dan yang mereka lakukan, mengandung materi pelajaran, hanya saja pembelajaran tersebut didesain menyerupai permainan.

Selain itu, webbed learning pada pembelajaran tematik di MIN 1 Probolinggo juga menggunakan pendekatan scientific learning, dengan menerapkan lima kegiatan dalam proses pembelajaran. Lima kegiatan tersebut diantaranya adalah mengamati, menanya, mengumpulkan informasi dan mencoba, mengasosiasi/mengolah informasi, kegiatan yang terakhir adalah mengkomunikasikan.

4. Mengkaji Media dan Sumber Belajar

Penerapan Webbed learning pada pembelajaran tematik bagi siswa inklusif di MIN 1 Probolinggo dilakukan dengan pembuatan media pembelajaran yang unik, menarik dan mampu membangkitkan motivasi belajar peserta didik. Media pembelajaran unik dan menarik mempunyai banyak kegunaan untuk kegiatan pembelajaran. Media pembelajaran bisa mengalihkan perhatian siswa pada halhal yang membuat siswa tidak fokus belajar. Media yang unik dan menarik dapat mempermudah penyampaian pesan pembelajaran antara guru dan peserta didik. Dengan menggunakan media, ada interaksi antara guru dengan peserta didik, dan peserta didik mampu menggunakan media tersebut sehingga proses pembelajaran lebih efektif dan efisien.

Untuk mengaplikasikan media dan sumber belajar harus disesuaikan dengan tema dan lingkungan. Guru bisa menggunakan media yang ada di dalam kelas atau membuat sendiri media pembelajaran untuk mempermudah peserta didik memahami materi yang dijelaskan guru. Mengkaji sumber belajar yang akan digunakan siswa, dan mengecek kelayakan sumber belajar serta menyediakan lingkungan belajar.

5. Kulminasi (sharing) dalam Bentuk Evaluasi Pembelajaran. 
AL-MUDARRIS:journal of education, Vol. 2. No. 1 April 2019, ISSN: 2620-5831 (print), ISSN: 2620-4355(online)

DOI:

Setelah pembelajaran tematik dilaksanakan dengan webbed learning di MIN 1 Probolinggo, dilakukan evaluasi sesuai dengan karakter siswa yang berbasis pada authentic assessment. Untuk mengevaluasi tingkat keberhasilan siswa dalam mengikuti pembelajaran, guru harus menilai semua kegiatan siswa, seperti penilaian keaktifan siswa, penilaian sikap (akhlaq), penilaian pengetahuan, penilaian keterampilan, penilaian lisan, penilaian tertulis. Penilaian berbasis authentic assessment ini akan berkelanjutan untuk mengetahui perkembangan siswa. ${ }^{45}$

Penerapan webbed learning pada pembelajaran tematik terhadap siswa yang heterogen dan memiliki karakter yang berbeda-beda (normal dan inklusif), dengan menggunakan active learning dengan prinsip joyfull learning dan menggunakan media dan sumber belajar yang tepat guna, ternyata mampu menciptakan pembelajaran yang kondusif dan efektif di MIN 1 Probolinggo.

\section{E. KESIMPULAN}

Pendidikan inklusif merupakan sistem layanan pendidikan yang menerima serta mengadopsi peserta didik berkebutuhan khusus agar mendapatkan pendidikan yang sama dengan peserta didik normal, dan berkumpul dalam satu ruangan. Tidak ada perbedaan antara peserta didik berkebutuhan khusus dengan peserta didik lainnya. Hal ini ditujukan untuk memberikan kesempatan kepada semua peserta didik yang memiliki kelainan mental, fisik, emosional, dan sosial atau memiliki kecerdasan atau bakat istimewa guna memperoleh pendidikan yang berkualitas sesuai dengan kebutuhan dan kemampuan masing-masing peserta didik.

Model pembelajaran spider webbed/webbed ditujukan untuk membantu mempermudah peserta didik hiperaktif di MIN 1 Probolinggo. Model webbed learning

${ }^{45}$ Masrurotul Mahmudah Binti Khoiriyah, Nur Laili, 'Pendekatan Contextual Teaching and Learning (CTL) Untuk Meningkatkan Hasil Belajar Aqidah Akhlaq', Al-Mudarris: Journal of Education, 1.2 (2018), 62-67. 
mampu meningkatkan hasil belajar peserta didik yang mengalami kesulitan dalam belajar, khususnya peserta didik hiperaktif, karena webbed learning merupakan pembelajaran yang menggunakan metode bervariasi dan menyenangkan, akhirnya mampu membuat peserta didik aktif dalam mengikuti pembelajaran. Model pembelajaran webbed ini tidak memeta-metakan mata pelajaran, sehingga dalam satu pertemuan tidak terasa siswa menerima beberapa mata pelajaran yang sudah dikonsep oleh pendidik .

\section{DAFTAR PUSTAKA}

Alfiah, and Siti Fitriana, 'Pengaruh Pembelajaran Terpadu Model Webbed (Jaring Laba-Laba) Dan Model Fragmented (Penggalan) Terhadap Hasil Belajar Unggah-Ungguhing Bahasa Jawa Di Kelas Awal Sekolah Dasar', Journal Universitas PGRI Semarang, 2012

Anafiah, Siti, and Dinar Westri Andini, 'Pelaksanaan Pendidikan Inklusi Di SD Tumbuh 2 Yogyakarta', Wacana Akademika, 2 (2018), 73-84

Astanu, Nofita Sari, Sowiyah, and Irwan Suntoro, 'Implementasi Program Pendidikan Inklusif (Studi Evaluasi Metode CIPP Di SMA Negeri 2 Metro)', JMMP, 1 (2015)

Baharun, Hasan, and Robiatul Awwaliyah, 'Pendidikan Inklusi Bagi Anak Berkebutuhan Khusus Dalam Perspektif Epistemologi Islam', MODELING: Jurnal Program Studi PGMI, 5 (2018), 57-71

Bali, Muhammad Mushfi El Iq, Strategi Pembelajaran Pendidikan Agama Islam (Probolinggo: Pustaka Nurja, 2018)

Bines, Hazel, and Philippa Lei, 'International Journal of Educational Development Disability and Education: The Longest Road to Inclusion', International Jurnal of Education Development, 31 (2011), 419-24 <http://dx.doi.org/10.1016/j.ijedudev.2011.04.009>

Binti Khoiriyah, Nur Laili, Masrurotul Mahmudah, 'Pendekatan Contextual Teaching and Learning (CTL) 
DOI:

Untuk Meningkatkan Hasil Belajar Aqidah Akhlaq', Al-Mudarris : Journal of Education, 1 (2018), 62-67 Eka, Jaya, 'Pendidikan Multikultur: Membangun Keberagaman Inklusif Dan Moderat Di Kalimantan', Jurnal KHAZANAH PENDIDIKAN, 5 (2013), 1-9

Fogarty, Robin, 'Ten Ways to Integrate Curriculum', Integrating the Curriculum, 1991, 61-65

Hernawan, Asep Herry, 'Pengembangan Model Pembelajaran Tematik Di Kelas Awal Sekolah Dasar', 2009

Ilham, Moch Wahid, 'MEMBANGUN HIGH ORDER THINKING ( HOT ) PESERTA DIDIK MELALUI CONTEXTUAL TEACHING LEARNING ( CTL ) DI MADRASAH', Jurnal Islam Nusantara, 1 (2017), 217-27

Iqrom, Pahrizal, Andi Gani, and Khairul Muluk, 'Manajemen Pelayanan Pendidikan Inklusif', Jurnal Pendidikan Humaniora, 2 (2014), 322-26

Islam, Syaiful, Hasan Baharun, Chusnul Muali, Moh Idil Ghufron, and Muhammad Mushfi El Iq Bali, 'To Boost Students 'Motivation and Achievement through Blended Learning', Journal of Physics: Conference Series, 2018, 1-11

Izzah, Ismatul, 'PERAN PENDIDIKAN AGAMA ISLAM DALAM MEMBENTUK MASYARAKAT MADANI', Jurnal Pedagogik, 5 (2018), 50-68

John, Yvonne J, "A “ New " Thematic , Integrated Curriculum for Primary Schools of Trinidad and Tobago: A Paradigm Shift', International Journal of Higher Education, 4 (2015), 172-87 <http://dx.doi.org/10.5430/ijhe.v4n3p172>

Martika, Tias, and Abdul Salim, 'Comparative Study of Regular Teachers ' Special Education Pedagogy Competence Level In Elementary and Senior High Inclusive School', Journal of ICSAR, 1 (2017), 32-35

Meliastari, 'Mengurangi Hiperaktifitas Pada Anak Attention Deficit/Hiperactivity Disorder (ADHD) Melalui Permainan Tradisional Teropa Tempurung, Ilmiah 
AL-MUDARRIS:journal of education, Vol. 2. No. 1 April 2019, ISSN: 2620-5831 (print), ISSN: 2620-4355(online)

DOI: $10.32478 /$ al-mudarris.v2i1.220

Pendidikan Khusus, 1 (2012), 283-94

Muali, Chusnul, Syaiful Islam, and Muhammad Mushfi El

Iq Bali, 'Free Online Learning Based On Rich Internet Applications; The Experimentation Of Critical Thinking About Student Learning Style', Journal of

Physics: Conference Series, 1114 (2018), 1-6

Mumpuniarti, Fathurroman, and Sukinah, 'Value-Based

Education Model to Build Students of Inclusive Elementary School ' S Character', DiIJE, 2 (2014), 110

Murniarti, Erni, and Nouf Zahra Anastasia, 'Pendidikan Inklusif Di Tingkat Sekolah Konsep, Implementasi, Dan Strategi', JDP, 9 (2016), 9-18

Mushfi, Muhammad, and El Iq, 'MODEL INTERAKSI SOSIAL DALAM MENGELABORASI KETERAMPILAN SOSIAL', Jurnal Pedagogik, 4 (2017), 211-27

Pangesti, Putri, Suwarno, 'Analisis Tentang Anak Hiperaktif Dan Upaya Mengatasinya Pada Siswa Kelas IIISD Muhammadiyah 5 Surakarta Tahun Ajaran 2015/2016', The Progressive and Fun Education Seminar, 2016, 612-16

Rahim, Abdul, 'Pendidikan Inklusif Sebagai Strategi Dalam Mewujudkan Pendidikan Untuk Semua', Trihayu, Jurnal Pendidikan Ke-SD-An, 3 (2016), 68-71

Salim, Abdul, 'The Prevalence of Children With Special

Needs In Inclusive Elementary Schools in Iodine

Deficiency Area', DIJE, 1 (2013), 40-46

Sari Rudiyati, 'Peningkatan Kompetensi Guru Sekolah Inklisif Dalam Penanganan Anak Berkebutuhan Pendidikan Khusus Melalui Pembelajaran

Kolaboratif', UNY JOURNAL, 2013, 296-306

Setiyorini, Nunung Dwi, 'Pembelajaran Kontekstual IPA

Melalui Outdoor Learning Di SD Alam Ar-Ridho Semarang', Al-Mudarris: Journal of Education, 1 (2018), 30-38

Suharta, 'Pendekatan Inklusif Dan Deliberatif Dalam Perencanaan Pendidikan Kecakapan Hidup Dan 
AL-MUDARRIS:journal of education, Vol. 2. No. 1 April 2019, ISSN: 2620-5831 (print), ISSN: 2620-4355(online)

DOI:

Pemberdayaan Masyarakat Miskin', Diklus Edisi 6, 2007, 64-84

Suwaryantini, Ni, Sulastri, and Ni Suami, 'Pengaruh Media

Kartu Berseri Melalui ModelPembelajaran Terpadu

Tipe Webbed Terhadap Hasil Belajar Membaca

Permulaan', E-Journal MIMBAR Universitas

Pendidikan Ganesha, 2 (2014)

Syam, Tasrif, 'Memperkenalkan Hak Asasi Manusia Pada

Siswa ( SD ) Melalui Pembelajaran Terpadu Dengan

Model Webbed', Keguruan, 1 (2013), 29-32

Trimo, 'Manajemen Sekolah Penyelenggara Pendidikan

Inklusif: Kajian Aplikatif Pentingnya Menghargai

Keberagaman Bagi Anak-Anak Berkebutuhan

Khusus', JMP, 1 (2012), 224-39

Wati, Sinu, M Syukri, and Wahyudi, 'Pengembangan Alat

Permainan Edukatif Dalam Pembelajaran Model

Webbed Pada Anak Usia 5-6 Tahun', JIPP, 3 (2014), $1-16$

Wijayanti, Hanik, Suhartono, and Joharman, 'Penggunaan

Model Pembelajaran Tematik (Webbed) nDalam

Peningkatan Pemebelajaran Tema Pengalaman Di

Kelas II SD Negeri 5 Kebumen Tahun Ajaran 2013/2014', FKIP UNS JOURNAL SYSTEMS, 5 (2014), 2017

Yusuf, Muhammad, and Ana Ratna Wulan, 'Penerapan

Model Pembelajaran Discovery Learning

Menggunakan Pembelajaran Tipe Shared Dan Webbed

Untuk Meningkatkan Keterampilan Proses Sains', JPPPF-Jurnal Penelitian \& Pengembangan

Pendidikan Fisika, 1 (2015), 19 